Estela Prieto, Fco. Borja.

Alumno 2ㅇ año en la Escuela de Doctores de la UPV.

\title{
El Individuo en la Pantalla: La Soledad del Narciso Contemporáneo.
}

\author{
TIPO DE TRABAJO
}

Póster.

PALABRAS CLAVE

Soledad, Aislamiento, Narciso, Nuevas Tecnologías de la Comunicación, Redes sociales, Identidad.

\section{KEY WORDS}

Loneliness, Isolation, Narcissus, Social Media, Identity, Hikikomori, New communication technologies.

\section{RESUMEN}

El siguiente trabajo tiene como objetivo plasmar cómo el nuevo modelo comunicativo nos aísla cada vez más del resto de los seres humanos. Este cambio de paradigma en la forma de relacionarnos nos ha llevado a una paradoja: Por miedo a estar solos buscamos cada vez más contactos utilizando las nuevas tecnologías de la comunicación, pero a la vez, estamos perdiendo cada vez más el trato cara a cara, convirtiendo las calles de las ciudades dónde habitamos en un escenario de tránsito donde los individuos caminan ajenos al resto, sumergidos en su mundo y absorbidos por la pantalla. La búsqueda de la conexión lleva al aislamiento. Cada vez más solos. Además, el ser humano contemporáneo ya no busca su reflejo en el espejo, sino en las pantallas. Y estás nos devuelven un reflejo pervertido, una identidad exaltada y fragmentada que potencia aún más esa sensación de soledad y de extrañeza a la hora de asentar nuestra identidad.

\section{ABSTRACT (En inglés)}

The following dissertation aims to capture how the new communication paradigm increasingly isolates us from the rest of the humanity. This paradigm shift in the way we relate with other people has led to a paradox: As we are afraid to be alone, we seek contacts increasingly using new technologies, but at the same time, we are losing increasingly dealing face to face, turning the streets of the cities where we inhabit a traffic scenario where individuals walk outside the rest, immersed in their world and absorbed by the screen. The search for the connection leads to isolation. Increasingly alone. In addition, the contemporary man no longer seeks his own reflection in the mirror, but on the screens. And these we return a perverted reflection, exalted and fragmented identity that further enhances the feeling of loneliness and strangeness seat when our real identity.

\section{CONTENIDO}

Con este trabajo intentamos reflejar una mirada a ese Narciso que habita en las ciudades posmodernas, plasmando su soledad y su aislamiento del resto, en parte, por las nuevas tecnologías de la comunicación que lo absorben volviéndolo ajeno a todo lo que ocurre. Este Narciso contemporáneo se encuentra aislado, por un lado, la sociedad en la que vive fomenta una producción de un individuo cada vez más narcisista. Aparte, somos cada vez más "sobjetos" ${ }^{1}$, es decir, el individuo se ve cada vez más como un objeto de

\footnotetext{
${ }^{1}$ VERDÚ, Vicente. Yo y tú, objetos de lujo. El personismo: la primera revolución cultural del siglo XXI. Barcelona, Random House Mondadori, 2005.
} 
consumo. También las relaciones están concebidas como un producto con fecha de caducidad ${ }^{2}$. Por otro lado en la ciudad, el aumento de los "No lugares" ${ }^{3}$ como aeropuertos, estaciones de metros, cajeros etc. Y la disminución de los espacios públicos y de relación ha empujado al individuo a sumergirse en el mundo virtual gracias a las nuevas tecnologías de la comunicación. Sin embargo, estas conexiones que se crean mediante las nuevas tecnologías son generalmente débiles y superficiales como para llegar a formar un vínculo fuerte. Además, este individuo quiere estar con los demás, pero también estar en otros lugares, conectado con los que quiere estar consiguiendo así que esa conexión derive finalmente en una completa aislación por su parte ${ }^{4}$.

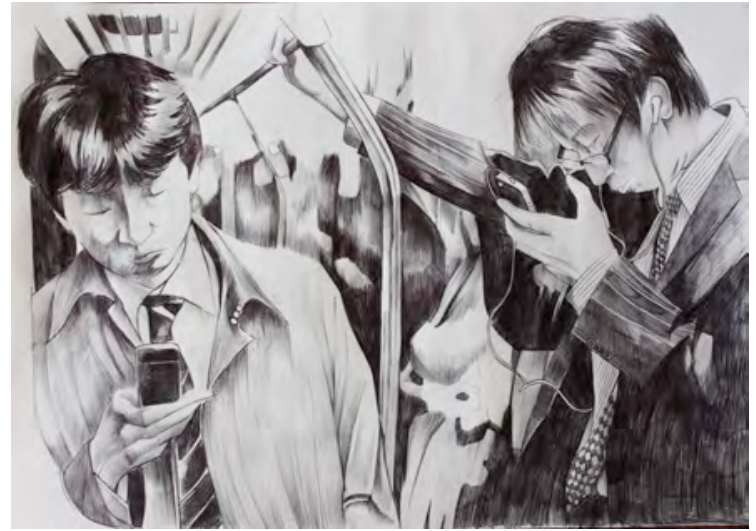

Fco Borja Estela, Soledad y Anonimato de la vida en las grandes ciudades VI, 41'7 x $30 \mathrm{~cm}$. Bolígrafo sobre papel. 2013

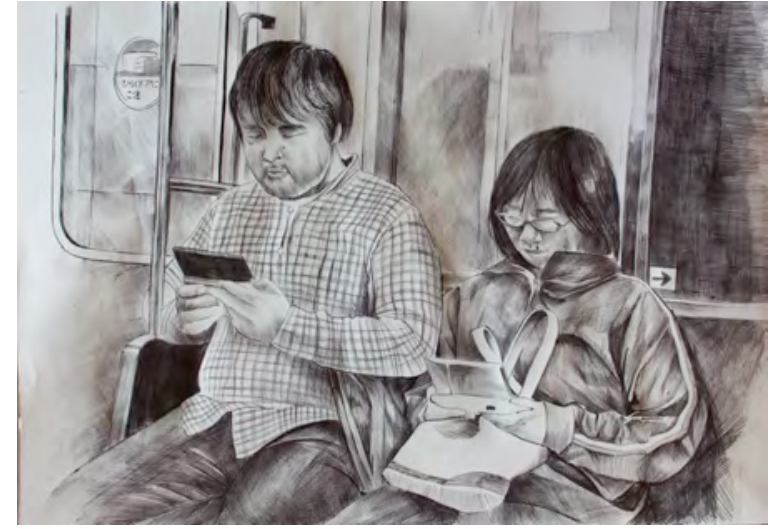

Fco Borja Estela, Soledad y Anonimato de la vida en las grandes ciudades VIII $41 ' 7$ x $30 \mathrm{~cm}$. Bolígrafo sobre papel. 2013

Todo esto deriva en una hegemonía absoluta de la pantalla ya que según la psicóloga Sherry Turkle la tecnología nos llega allí donde somos más vulnerables ${ }^{5}$. Vemos en el dispositivo móvil a ese alguien que nos escucha cuando el resto no lo hace y es muy gratificante tener a ese oyente automático. Las nuevas tecnologías de la comunicación nos ofrecen tres gratificantes fantasías: La primera es que podemos poner la atención en donde queramos tenerla; la segunda, que siempre seremos escuchados; y la tercera, que nunca estaremos solos. Y esa idea es clave para cambiar nuestra forma de pensar. Estar solos parece haberse convertido en un problema que hay que resolver y la gente lo soluciona conectándose. Y esa conexión permanente está cambiando la forma en la que la gente piensa de sí misma ya que si no tenemos conexión no nos hallamos en nosotros mismo. Por eso nos conectamos cada vez más pero en el proceso nos disponemos a estar más aislados.

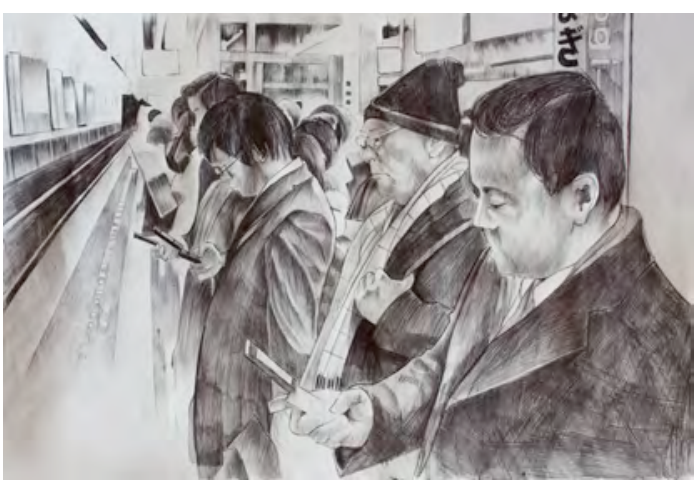

Fco Borja Estela, Soledad y Anonimato de Ia vida en las grandes ciudades IV, 41'7 x $30 \mathrm{~cm}$. Bolígrafo sobre papel. 2013

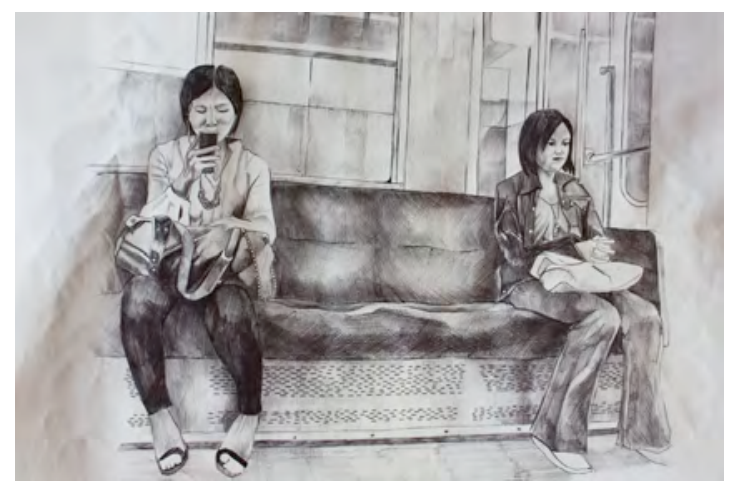

Fco Borja Estela, Soledad y Anonimato de la vida en las grandes ciudades III, 41'7 x $30 \mathrm{~cm}$. Bolígrafo sobre papel. 2013

\footnotetext{
${ }^{2}$ BAUMAN, Zygmunt. Modernidad Líquida. Buenos Aires, Fondo de Cultura Económica de Argentina, S.A. 2002

${ }^{3}$ AUGÉ, Marc. Los <<No lugares >>. Espacios del anonimato. Una antropología de la sobremodernidad. Barcelona. Editorial Gedisa, S.A. 1998.

${ }^{4}$ TEDXUIUC- Sherry Turkle- Alone Together. [En línea]. En You Tube, el 25-03-2011.[Consultado el 20-05-2013] Disponible en:

http://www.youtube.com/watch?v=MtLVCpZliNs

${ }_{5}^{5}$ lbídem.
} 
Un ejemplo es la sociedad japonesa. Cuna y paraíso tecnológico, es el país más adelantado en cuanto a tecnologías de la comunicación sin embargo, las relaciones interpersonales han mermado quedando relegadas a un segundo plano. Resultado de esa falta de comunicación y de empatía es que casi un tercio del país ha dejado de tener relaciones sexuales ${ }^{6}$. En el documental El Imperio de los SinSexo se reflexiona sobre los diversos aspectos que han conllevado a esta situación siendo el más clave la desaparición de la comunicación cara a cara. Además el Hikikomori, que se convierte en el aislamiento hecho carne. Refugiados en su particular burbuja hermética de tecnología, aislándose de la sociedad. Les resulta más fácil moverse en un mundo virtual que en un mundo real... Sabiendo esto, ¿Japón es muy diferente o sencillamente va por delante?

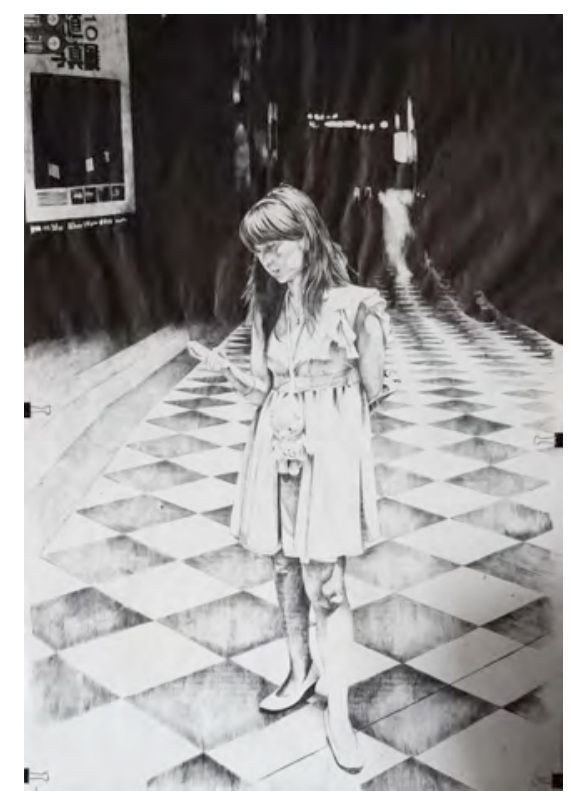

Fco Borja Estela, Soledad y Anonimato de Ia vida en las Grandes ciudades XII, 100x 70 cm. Bolígrafo sobre papel. 2014

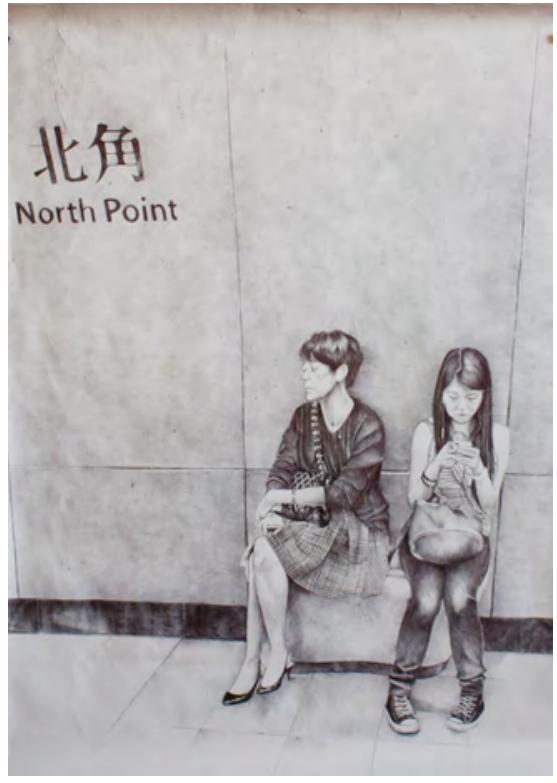

Fco Borja Estela, Soledad y Anonimato de la vida en las Grandes ciudades XI, 70x $50 \mathrm{~cm}$. Bolígrafo sobre papel. 2014

Por eso, la obra que presentamos se basa en el paradigma japonés. El bolígrafo como herramienta nos remite a las décadas de los 60 , 70 y 80 del S. XX dónde se creía que los avances tecnológicos nos asegurarían una vida de bienestar. Así, cuando nos habla de las imágenes que las pantallas reproducen todos los días, la mirada nostálgica carga de valor nuestra destreza manual, al material y al soporte. Son escenas de ensimismamiento de la población. Una marea de de gente dirigida a cualquier lugar, ajena al resto, sentada en el metro, solamente teniendo relación con sus keitai. El carácter duro de las grisallas, o del contorno de los individuos les da un aire de apunte que sólo está centrado en captar esa sensación de soledad aún estando acompañado por muchas personas. Solamente existen ellos y la ceguera blanca emanada de las pantallas de sus móviles.

\footnotetext{
${ }^{6}$ CAULE, Pierre. El Imperio de los SinSexo. Francia, Kami Productions y France Télévisions. 2012. 53 minutos.
} 